\title{
Efficacy of statins for primary prevention in people at low cardiovascular risk: a meta-analysis
}

\author{
Marcello Tonelli MD SM, Anita Lloyd MSc, Fiona Clement PhD, Jon Conly BA, Don Husereau BScPharm MSc, \\ Brenda Hemmelgarn PhD MD, Scott Klarenbach MD MSc, Finlay A. McAlister MD MSc, \\ Natasha Wiebe MMath PStat, Braden Manns MD MSc; for the Alberta Kidney Disease Network
}

See related research article by Conly and colleagues at www.cmaj.ca/lookup/doi/10.1503/cmaj.101281 and related commentary by Gupta at www.cmaj.ca/lookup/doi/10.1503/cmaj.111674

\section{- Abstract}

Background: Statins were initially used to improve cardiovascular outcomes in people with established coronary artery disease, but recently their use has become more common in people at low cardiovascular risk. We did a systematic review of randomized trials to assess the efficacy and harms of statins in these individuals.

Methods: We searched MEDLINE and EMBASE (to Jan. 28, 2011), registries of health technology assessments and clinical trials, and reference lists of relevant reviews. We included trials that randomly assigned participants at low cardiovascular risk to receive a statin versus a placebo or no statin. We defined low risk as an observed 10 -year risk of less than $20 \%$ for cardiovascular-related death or nonfatal myocardial infarction, but we explored other definitions in sensitivity analyses.

Results: We identified 29 eligible trials involving a total of 80711 participants. All-cause mortality was significantly lower among patients receiving a statin than among controls (relative risk [RR] 0.90, 95\% confidence interval [Cl] 0.84-0.97) for trials with a 10-year risk of cardiovascular disease $<20 \%$ [primary analysis] and $0.83,95 \% \mathrm{Cl} 0.73-0.94$, for trials with 10 -year risk $<10 \%$ [sensitivity analysis]). Patients in the statin group were also significantly less likely than controls to have nonfatal myocardial infarction (RR $0.64,95 \% \mathrm{Cl}$ $0.49-0.84$ ) and nonfatal stroke (RR 0.81, 95\% $\mathrm{Cl}$ 0.68-0.96). Neither metaregression nor stratified analyses suggested statistically significant differences in efficacy between highand low-potency statins, or larger reductions in cholesterol.

Interpretation: Statins were found to be efficacious in preventing death and cardiovascular morbidity in people at low cardiovascular risk. Reductions in relative risk were similar to those seen in patients with a history of coronary artery disease.
A lthough statins are known to improve survival and relevant clinical outcomes in high-risk populations, ${ }^{1}$ evidence of their clinical benefit in lower risk populations is more equivocal. Initially, low-risk populations were defined by the absence of known coronary artery disease (and their treatment was termed "primary prevention"). However, it was subsequently recognized that these populations included both patients at very high risk of coronary artery disease (e.g., those with severe peripheral vascular disease) and those at very low risk (e.g., those aged $<40$ years who have no diabetes or hypertension and have lowdensity lipoprotein cholesterol level of less than $1.8 \mathrm{mmol} / \mathrm{L})$. Accordingly, current guidelines for the use of statins are based on the projected risk of an atherosclerotic event rather than solely on the presence or absence of known coronary artery disease. ${ }^{2,3}$

Results of the recent JUPITER study (Justification for the Use of Statins in Prevention: an Intervention Trial Evaluating Rosuvastatin) ${ }^{4}$ have renewed enthusiasm for the use of statins in people without a history of coronary artery disease and have generated further controversy as to whether high-potency statins such as rosuvastatin and atorvastatin lead to better clinical outcomes than low-potency statins such as pravastatin, simvastatin, fluvastatin and lovastatin. We did a systematic review of randomized trials to assess the efficacy and harms of statins in people at low cardiovascular risk, including indirect comparisons of high-potency and low-potency statins.
Competing interests:

Marcello Tonelli has received research support from Pfizer; in 2011 he served on an advisory board for Merck, providing expert opinion on global chronic

kidney disease and cardiovascular disease. Brenda Hemmelgarn has received research support from Merck and Amgen. Braden Manns has received research support from Merck Canada. No competing interests declared by the other authors.

This article has been peer reviewed.

Correspondence to:

Dr. Marcello Tonelli, mtonelli -admin@med.ualberta.ca

CMAJ 2011. DOI:10.1503 /cmaj.101280 


\section{Methods}

We performed a systematic review of published and unpublished randomized controlled trials that compared statins with no statin or placebo. We used accepted methods for literature searches, article selection, data extraction and risk-of-bias assessment. The review was reported according to accepted guidelines. ${ }^{5,6}$

\section{Literature search}

We searched MEDLINE (1950 to Jan. 28, 2011) and EMBASE (1950 to Jan. 28, 2011). Details of the search strategy appear in Appendix 1 (available at www.cmaj.ca/lookup/suppl/doi:10.1503 /cmaj.101280/-/DC1). Because of high search yields, an update of a modified version of the National Institute for Health and Clinical Excellence search ${ }^{7}$ was performed, with elimination of studies published before 2003. Searches were not restricted by language (when a translator could be found).

We also searched registries of health technology assessments and clinical trials, conducted manual searches of reference lists of relevant reviews, and contacted Canadian manufacturers of statins (Astra Zeneca, Merck Frosst, Pfizer, Bristol Myers Squibb, Novartis) for additional studies and unpublished reports of trials.

\section{Study selection and validity assessment}

We included parallel-group randomized controlled trials if they included people 16 years or older who were at low cardiovascular risk (as defined in the next paragraph), the follow-up period was at least six months, and an eligible statin (atorvastatin, fluvastatin, lovastatin, pravastatin, rosuvastatin or simvastatin) was compared with no statin (placebo or standard care). We categorized statins according to their pharmacologic effect on lowering cholesterol as either low potency (fluvastatin, lovastatin, pravastatin and simvastatin) or high potency (atorvastatin and rosuvastatin). ${ }^{8}$ To be eligible, studies also had to report one or more of the following outcomes: all-cause mortality, unstable angina, acute myocardial infarction (fatal or nonfatal), stroke or transient ischemic attack (fatal or nonfatal), surgical or percutaneous revascularization, length of stay, quality of life, persistence on statin therapy, and adverse events. Trials with fewer than 30 participants per study arm were excluded to improve the efficiency of the work without an appreciable loss of power. ${ }^{9}$

Trials were considered to have enrolled participants at low cardiovascular risk if the 10-year risk of cardiovascular-related death or nonfatal myocardial infarction among participants was less than $20 \%,{ }^{10}$ as assessed by extrapolation of observed risk in the control group of each trial. In general, this corresponded to participants who were free from cardiovascular disease (i.e., no prior acute coronary syndrome or coronary revascularization, no prior ischemic stroke and no prior revascularization or loss of limb owing to peripheral arterial disease) and diabetes. Data from trials in which some, but not all, participants had known cardiovascular disease were included if the control group had a low cardiovascular risk (as defined above).

In sensitivity analyses, we calculated the estimated 10-year risk of cardiovascular-related death or nonfatal myocardial infarction for the average participant in each trial, using mean baseline characteristics from the control group and two commonly used formulas from D'Agostino and colleagues ${ }^{11}$ and the Third Adult Treatment Panel. ${ }^{12}$ We also used a number of other definitions for low risk in sensitivity analyses.

Two reviewers screened each citation. Trials considered to be relevant by one or both reviewers were retrieved, and the full text was independently assessed by two reviewers for inclusion. Disagreements were resolved by a third party through consensus.

Two reviewers independently assessed each study's risk of bias using a condensed version of the Chalmers Index ${ }^{13}$ as well as other characteristics that influence the risk of biased estimates of effectiveness in meta-analyses. ${ }^{14-16}$ Disagreements were resolved by a third party through consensus.

\section{Data extraction}

One reviewer extracted data from selected trials, and a second reviewer checked the data for accuracy. Results of intention-to-treat analyses were collected if reported.

We classified adverse events as serious if they were defined as such by the primary authors or if their severity was unspecified but they led to withdrawal from therapy or study. We also collected data on the incidence of new diabetes, cancer and rhabdomyolysis. Myocardial infarctions were classified as fatal, nonfatal or fatal/nonfatal; those in the fatal/nonfatal category were from studies that did not specify the type of myocardial infarction or separate totals for fatal and nonfatal myocardial infarctions. Strokes were classified in a similar manner. Angina was classified as unstable if defined as such by the primary authors, if it required admission to hospital or if it necessitated revascularization. Angina that did not meet these criteria was classified as "unspecified" angina. Types of revascularization included coronary artery bypass graft surgery, percutaneous coronary intervention, percutaneous transluminal 
coronary angioplasty, interventional vascular procedure, coronary revascularization, arterial revascularization and coronary angioplasty. For studies in which the number of cardiovascular-related deaths or nonfatal myocardial infarctions was unclear, we contacted the original authors for information so that we could calculate the 10year risk.

\section{Data synthesis and analysis}

We pooled the results using the random-effects model described by DerSimonian and Laird. ${ }^{17}$ We used relative risks (RRs) to summarize dichotomous results. We quantified statistical heterogeneity using the $I^{2}$ statistic and used "small," "moderate" and "large" to describe values of $25 \%, 50 \%$ and $75 \% .18,19$ A weighted regression test ${ }^{20}$ was used to test for publication bias.

We used univariable and bivariable metaregression analyse ${ }^{18}$ to examine whether the following variables influenced the association between statin use and all-cause mortality: duration of study, year of study, baseline cholesterol levels, observed annual cardiovascular risk in the control arm, the absolute and percent change in low-density lipoprotein cholesterol from baseline in the statin arm, the point at which low-density lipoprotein cholesterol was measured, daily initial dose of statin, potency of statin (high v. low), mean age of participants, proportion of participants who were male, proportion who had diabetes, proportion who had hypertension, and risk-of-bias items.

The number needed to treat and the absolute risk reduction were calculated for outcomes with statistically significant relative risks. The number needed to treat indicates the number of patients who need to be given statin treatment to prevent one event and is the reciprocal of the absolute risk reduction (difference in probabilities of an event between treatment and control groups). ${ }^{21}$

In subgroup analyses, we examined all-cause mortality and other clinical outcomes for trials stratified by statin potency (high v. low). We also explored the relative effects of statins using a method of indirect comparison of treatments described by Bucher and colleagues, ${ }^{22}$ a technique that facilitates the comparison of any two statins not directly compared in any one study. Here, the magnitude of treatment effects (e.g., relative risk) for the direct evidence of treatment $\mathrm{A}$ versus $B$ and treatment $B$ versus $C$ were compared with acquired indirect evidence of treatment $\mathrm{A}$ versus $\mathrm{C}$.

Analyses were conducted using RevMan Version 4.2 (The Cochrane Collaboration, 2002) and Stata/MP 11.2 software (Stata Corp, 2011).

\section{Results}

\section{Literature search}

Of the 15250 articles identified, $29(n=80711)$ met our inclusion criteria (Figure 1). ${ }^{4,23-50}$ Atorvastatin was the study drug in six trials $(n=11894)$, fluvastatin in four trials $(n=2107)$, lovastatin in three $(n=15769)$, pravastatin in nine $(n=$ $30974)$, rosuvastatin in four $(n=19129)$ and simvastatin in three $(n=838)$. Twenty-two of the trials were placebo-controlled, and the remaining seven reported usual care, conventional treatment, standard treatment, no treatment or diet as the comparators. The median year of publication was 2004 (range 1991-2010). The median duration of follow-up was two years (range 0.5-5.3 years). Details of the studies are summarized in Table 1 (at the end of the article).

\section{Risk-of-bias assessment}

The 29 trials generally exhibited moderate risk of bias (Table 2, at the end of the article). A weighted regression test ${ }^{20}$ using all-cause mortality results detected no statistical evidence of publication bias (bias $=0.03, p=0.92$ ).

\section{Characteristics of participants}

The median age of the participants was 58 years (range 51-76), and the proportion who were

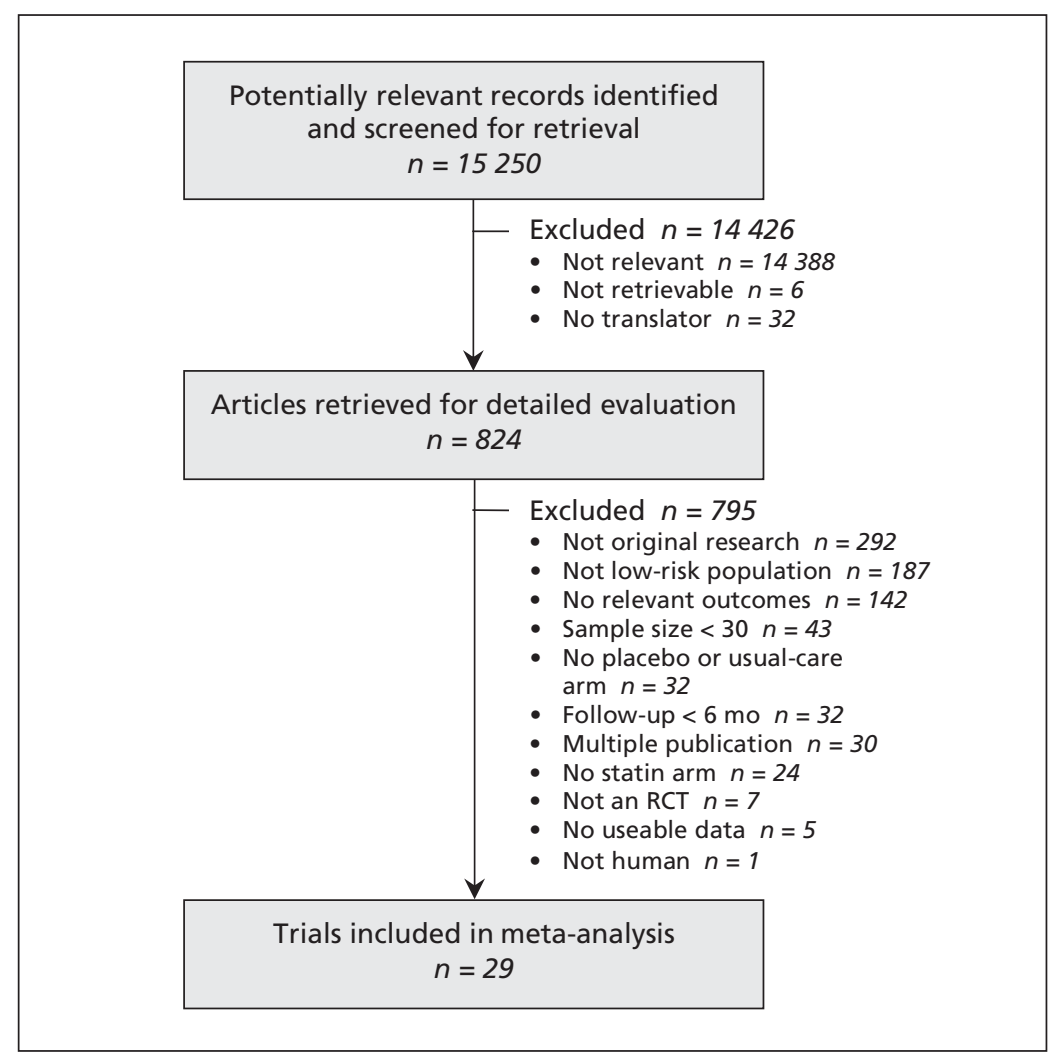

Figure 1: Selection of studies for inclusion in the meta-analysis. RCT = randomized controlled trial. 
male ranged from $0 \%$ to $100 \%$ (median $62 \%$ ). The median proportion of participants who had diabetes was $7 \%$ (range 0\%-35\%), and hypertension 47\% (range 16\%-100\%) (Table 1).

The baseline lipid levels in the included trials were: total cholesterol, median 6.0 (range 4.87.6) $\mathrm{mmol} / \mathrm{L}$; low-density lipoprotein cholesterol, median 4.0 (range 2.8-5.2) mmol/L; high-density lipoprotein cholesterol, median 1.3 (range 1.0 1.9) $\mathrm{mmol} / \mathrm{L}$; and triglycerides, median 1.7 (range 1.2-3.6) $\mathrm{mmol} / \mathrm{L}$. Seven studies reported baseline C-reactive protein levels: median 0.17 (range 0.15-7.7) mg/dL (16.6 [range 13.8-732.4] $\mathrm{nmol} / \mathrm{L}$ ). The mean 10-year risk of cardiovascular-related death or nonfatal myocardial infarction was $6 \%$ (range $0 \%-18 \%$ ).

\section{Outcomes}

Table 3 presents a summary of the relative risks (overall and stratified by high- and low-potency statins), number needed to treat and absolute risk reduction for all outcomes.

\section{All-cause mortality}

Twenty-three trials $(n=79495)$ reported all-cause mortality (Figure 2). The trial-level relative risk could not be estimated for four trials that reported no events in either group. ${ }^{51}$ From the remaining 19 trials $(n=78321)$, the pooled relative risk of death was significantly lower among statin recipients than among controls (RR $0.90,95 \%$ confidence interval $[\mathrm{CI}] 0.84-0.97 ; I^{2}=2.0 \%$ ).
In the metaregression analyses, none of the characteristics listed in the methods section (including baseline cholesterol levels or change in lipid levels during the trials) significantly modified the association between statin use and all-cause mortality at the level of $p<0.05$ (Appendix 2, available at www.cmaj.ca/lookup /suppl/doi:10.1503/cmaj.101280/-/DC1).

\section{Myocardial infarction}

Thirteen trials $(n=48023)$ reported the number of participants with fatal, nonfatal or unspecified myocardial infarctions. The pooled relative risk was significantly lower among statin recipients than among controls (RR $0.63,95 \%$ CI 0.50 $\left.0.79 ; I^{2}=13 \%\right]$.

From eight trials $(n=31424)$ that provided data on fatal myocardial infarctions, we found that the pooled relative risk did not differ significantly between treatment groups (RR 0.96, 95\% CI $0.5-1.85 ; I^{2}=0 \%$ ).

Ten trials $(n=49222)$ reported nonfatal myocardial infarctions. The pooled relative risk was significantly lower among statin recipients than among controls (RR $0.64,95 \%$ CI 0.49 $0.84 ; I^{2}=44 \%$ ) (Figure 3 ). After removing studies that enrolled people with prior myocardial infarction, we found that the point estimate was similar to the estimate from the primary analysis (eight trials, $n=48$ 595; RR 0.64, 95\% CI 0.48-0.86; moderate heterogeneity $\left.\left[I^{2}=54 \%\right]\right)$.

Table 3: Relative risk of serious outcomes associated with the use of statins in patients at low cardiovascular risk*

\begin{tabular}{|c|c|c|c|c|c|}
\hline Outcome & $\begin{array}{c}\text { Overall } \\
\text { RR }(95 \% \mathrm{Cl})\end{array}$ & $\begin{array}{l}\text { RR for high- } \\
\text { potency statins } \\
(95 \% \mathrm{Cl})\end{array}$ & $\begin{array}{l}\text { RR for low- } \\
\text { potency statins } \\
(95 \% \mathrm{Cl})\end{array}$ & $\begin{array}{c}\text { Number } \\
\text { needed to treat } \\
(95 \% \mathrm{Cl}) \dagger\end{array}$ & $\begin{array}{c}\text { Absolute risk } \\
\text { reduction, \% } \\
(95 \% \mathrm{Cl}) \dagger\end{array}$ \\
\hline Myocardial infarction & $0.63(0.50-0.79)$ & $0.47(0.31-0.71)$ & $0.68(0.53-0.87)$ & $216(160-381)$ & $0.46(0.26-0.63)$ \\
\hline Fatal myocardial infarction & $0.96(0.50-1.85)$ & $1.54(0.61-3.89)$ & $0.59(0.23-1.51)$ & - & - \\
\hline Fatal stroke & $0.91(0.65-1.29)$ & $0.50(0.13-2.0)$ & $0.95(0.67-1.35)$ & - & - \\
\hline Nonfatal stroke & $0.81(0.68-0.96)$ & $0.51(0.33-0.79)$ & $0.88(0.73-1.06)$ & 335 (199-1592) & $0.30(0.06-0.50)$ \\
\hline Unstable angina & $0.71(0.55-0.92)$ & $0.73(0.48-1.11)$ & $0.70(0.51-0.97)$ & $431(278-1563)$ & $0.23(0.06-0.36)$ \\
\hline Angina, type unspecified & $0.83(0.57-1.22)$ & $1.05(0.12-9.23)$ & $0.83(0.56-1.22)$ & - & - \\
\hline Cancer & $1.00(0.93-1.08)$ & $0.95(0.81-1.11)$ & $1.02(0.93-1.11)$ & - & - \\
\hline New diabetes & $1.05(0.84-1.32)$ & $1.17(1.04-1.32)$ & $0.76(0.56-1.02)$ & - & - \\
\hline
\end{tabular}




\section{Stroke}

Fourteen trials $(n=60841)$ reported the number of participants with fatal, nonfatal or undefined strokes. The pooled relative risk of stroke was significantly lower among statin recipients than among controls (RR $0.83,95 \%$ CI 0.74 $\left.0.93 ; I^{2}=0 \%\right)$.

Five trials $(n=36118)$ reported on the risk of fatal stroke; the pooled relative risk did not differ significantly between treatment groups (RR 0.91, 95\% CI $\left.0.65-1.29 ; I^{2}=0 \%\right)$. Nine trials $(n=$ 37333 ) reported the number of participants with nonfatal stroke; the pooled relative risk was significantly lower among statin recipients (relative risk $0.81[0.68-0.96] ; I^{2}=0 \%$ ) (Figure 4).

\section{Coronary revascularization}

Eight trials $(n=43708)$ reported the number of participants who underwent percutaneous or sur- gical coronary revascularization. The incidence of revascularization was significantly lower among statin recipients than among controls (RR $0.66,95 \%$ CI $0.57-0.77 ; I^{2}=7 \%$ ).

\section{Other outcomes}

Four trials $(n=35017)$ reported on the risk of unstable angina: the pooled relative risk was significantly lower among statin recipients than among controls (RR 0.71, 95\% CI 0.55-0.92; $\left.I^{2}=0 \%\right)$. Three trials $(n=9082)$ reported on the risk of unspecified angina: the pooled relative risk did not differ significantly between treatment groups (RR $0.83,95 \%$ CI $0.57-1.22 ; I^{2}=$ $0 \%$ ). Thirteen trials reported on the proportion of participants who adhered to statin therapy (range 63\%-98\%). Length of hospital stay, persistence on statin therapy and quality-of-life measures were not reported in any of the studies.

\begin{tabular}{|c|c|c|c|c|c|}
\hline \multirow[b]{2}{*}{ Study } & \multicolumn{2}{|c|}{ No. of events, $n / N$} & \multirow[b]{2}{*}{ RR $(95 \% \mathrm{Cl})$} & \multirow{2}{*}{$\begin{array}{c}\text { Favours } \\
\text { - statin }\end{array}$} & \multirow{2}{*}{$\begin{array}{l}\text { Favours no } \\
\text { statin } \longrightarrow\end{array}$} \\
\hline & Statin & No statin & & & \\
\hline \multicolumn{6}{|c|}{ Low-potency statin* } \\
\hline EXCEL 45 & 33/6 582 & $3 / 1663$ & $2.78(0.85-9.05)$ & & \\
\hline ACAPS 38 & $1 / 460$ & $8 / 459$ & $0.12(0.02-0.99)$ & $\leftarrow$ & \\
\hline KAPS ${ }^{41}$ & $3 / 224$ & $4 / 223$ & $0.75(0.17-3.30)$ & & \\
\hline WOSCOPS 43 & 106/3 302 & $135 / 3293$ & $0.78(0.61-1.01)$ & & \\
\hline CAIUS 42 & $1 / 151$ & $0 / 154$ & $3.06(0.13-74.51)$ & & $\Rightarrow$ \\
\hline AFCAPS/TexCAPS 39 & $80 / 3304$ & 77/3 301 & $1.04(0.76-1.41)$ & & \\
\hline KLIS 37 & $87 / 2219$ & $78 / 1634$ & $0.82(0.61-1.11)$ & & \\
\hline ALLHAT-LLT40 & $631 / 5170$ & $641 / 5185$ & $0.99(0.89-1.09)$ & & \\
\hline Bruckert et al. ${ }^{33}$ & $1 / 607$ & $1 / 622$ & $1.02(0.06-16.35)$ & $\leftarrow$ & $\rightarrow$ \\
\hline Muldoon et al.29 & $0 / 206$ & $0 / 102$ & Not estimable & & \\
\hline PHYLLIS 30 & $1 / 254$ & $0 / 254$ & $3.00(0.12-73.30)$ & & $\rightarrow$ \\
\hline PREVEND-IT31 & $13 / 433$ & $12 / 431$ & $1.08(0.50-2.34)$ & & \\
\hline Rejnmark et al. ${ }^{32}$ & $0 / 41$ & $0 / 41$ & Not estimable & & \\
\hline HYRIM28 & $4 / 283$ & $5 / 285$ & $0.81(0.22-2.97)$ & & \\
\hline $\mathrm{MEGA}^{24}$ & $55 / 3866$ & 79/3 966 & $0.71(0.51-1.00)$ & & \\
\hline ESPLANADE ${ }^{49}$ & $0 / 87$ & $0 / 93$ & Not estimable & & \\
\hline $\begin{array}{l}\text { Subtotal } \\
R^{2}=18.8 \%\end{array}$ & $1016 / 27189$ & $1043 / 21706$ & $0.90(0.79-1.03)$ & & \\
\hline \multicolumn{6}{|c|}{ High-potency statint } \\
\hline ASCOT-LLA 36 & $186 / 5168$ & $212 / 5137$ & $0.87(0.72-1.06)$ & $-\frac{1}{1}$ & \\
\hline Holmberg et al. ${ }^{26}$ & $5 / 70$ & $5 / 73$ & $1.04(0.32-3.45)$ & & \\
\hline Bone et al. 23 & $0 / 485$ & $0 / 119$ & Not estimable & & \\
\hline METEOR ${ }^{34}$ & $1 / 702$ & $0 / 282$ & $1.21(0.05-29.56)$ & $\leftarrow$ & $\rightarrow$ \\
\hline JUPITER 4 & $198 / 8901$ & 247/8 901 & $0.80(0.67-0.96)$ & $\rightarrow$ & \\
\hline $\mathrm{LEADe}^{46}$ & 9/314 & $6 / 325$ & $1.55(0.56-4.31)$ & & \\
\hline LORD $^{48}$ & $4 / 58$ & $5 / 65$ & $0.90(0.25-3.18)$ & & \\
\hline $\begin{array}{l}\text { Subtotal } \\
R^{2}=0 \%\end{array}$ & $403 / 15698$ & 475/14 902 & $0.85(0.74-0.96)$ & $\Delta$ & \\
\hline \multirow{3}{*}{$\begin{array}{l}\text { Overall } \\
I^{2}=2.0 \%\end{array}$} & $1419 / 42887$ & $1518 / 36608$ & $0.90(0.84-0.97)$ & : & \\
\hline & & & & $\begin{array}{llll}0.1 & 0.2 & 0.5 & 1\end{array}$ & 510 \\
\hline & & & & \multicolumn{2}{|c|}{ RR (95\% Cl) } \\
\hline
\end{tabular}

Figure 2: Risk of death from any cause associated with the use of statins (versus no statins) in patients at low cardiovascular risk (observed 10-year risk of cardiovascular-related death or nonfatal myocardial infarction $<20 \%$ ). A relative risk (RR) of less than 1.0 indicates fewer deaths with the use of statins. $\mathrm{Cl}=\mathrm{confi}$ dence interval. *Lovastatin, fluvastatin, pravastatin and simvastatin. tRosuvastatin and atorvastatin. For complete study names, see Box 1. 


\begin{tabular}{|c|c|c|c|c|c|}
\hline \multirow[b]{2}{*}{ Study } & \multicolumn{2}{|c|}{ No. of events, $n / N$} & \multirow[b]{2}{*}{$\mathrm{RR}(95 \% \mathrm{Cl})$} & \multirow{2}{*}{$\longleftarrow \begin{array}{c}\text { Favours } \\
\longleftarrow \text { statin }\end{array}$} & \multirow{2}{*}{$\begin{array}{l}\text { Favours no } \\
\text { statin } \longrightarrow\end{array}$} \\
\hline & Statin & No statin & & & \\
\hline \multicolumn{6}{|c|}{ Low-potency statin* } \\
\hline ACAPS $^{38}$ & $5 / 460$ & $5 / 459$ & $1.00(0.29-3.42)$ & & \\
\hline KAPS 41 & $3 / 224$ & $6 / 223$ & $0.50(0.13-1.97)$ & & \\
\hline WOSCOPS 43 & $143 / 3302$ & 204/3 293 & $0.70(0.57-0.86)$ & & \\
\hline CAIUS 42 & $1 / 151$ & $2 / 154$ & $0.51(0.05-5.56)$ & $\leftarrow$ & \\
\hline KLIS 37 & $36 / 2219$ & 20/1 634 & $1.33(0.77-2.28)$ & & \\
\hline Muldoon et al.29 & $0 / 206$ & $0 / 102$ & Not estimable & & \\
\hline Rejnmark et al. ${ }^{32}$ & $0 / 41$ & $0 / 41$ & Not estimable & & \\
\hline MEGA $^{26}$ & $16 / 3866$ & 30/3 966 & $0.55(0.30-1.00)$ & & \\
\hline ESPLANADE ${ }^{49}$ & $1 / 87$ & $0 / 93$ & $3.20(0.13-77.63)$ & & $\Rightarrow$ \\
\hline $\begin{array}{l}\text { Subtotal } \\
R^{2}=15.8 \%\end{array}$ & $205 / 10556$ & 267/9 965 & $0.77(0.59-1.00)$ & & \\
\hline \multicolumn{6}{|c|}{ High-potency statint } \\
\hline ASCOT-LLA 36 & $60 / 5168$ & $108 / 5137$ & $0.55(0.40-0.76)$ & $\rightarrow-$ & \\
\hline METEOR 34 & $1 / 702$ & $0 / 282$ & $1.21(0.05-29.56)$ & $\leftarrow$ & $\rightarrow$ \\
\hline JUPITER ${ }^{4}$ & 22/8901 & $62 / 8901$ & $0.35(0.22-0.58)$ & $\longrightarrow-$ & \\
\hline $\begin{array}{l}\text { Subtotal } \\
R^{2}=22.1 \%\end{array}$ & $83 / 14771$ & $170 / 14320$ & $0.47(0.34-0.67)$ & & \\
\hline Overall & $288 / 25327$ & $437 / 24285$ & $0.64(0.49-0.84)$ & & \\
\hline \multirow[t]{2}{*}{$I^{2}=44.3 \%$} & & & & $\begin{array}{llll} & 0.1 & 0.2 & 0.5\end{array}$ & $\begin{array}{ll}1 & 1 \\
5 & 10\end{array}$ \\
\hline & & & & $\mathbf{R R}(\mathbf{S}$ & $\% \mathrm{Cl})$ \\
\hline
\end{tabular}

Figure 3: Risk of nonfatal myocardial infarction associated with the use of statins (versus no statins) in patients at low cardiovascular risk (observed 10-year risk of cardiovascular-related death or nonfatal myocardial infarction $<20 \%$ ). A relative risk (RR) of less than 1.0 indicates fewer events with the use of statins. $\mathrm{Cl}=$ confidence interval. *Lovastatin, fluvastatin, pravastatin and simvastatin. tRosuvastatin and atorvastatin. For complete study names, see Box 1.

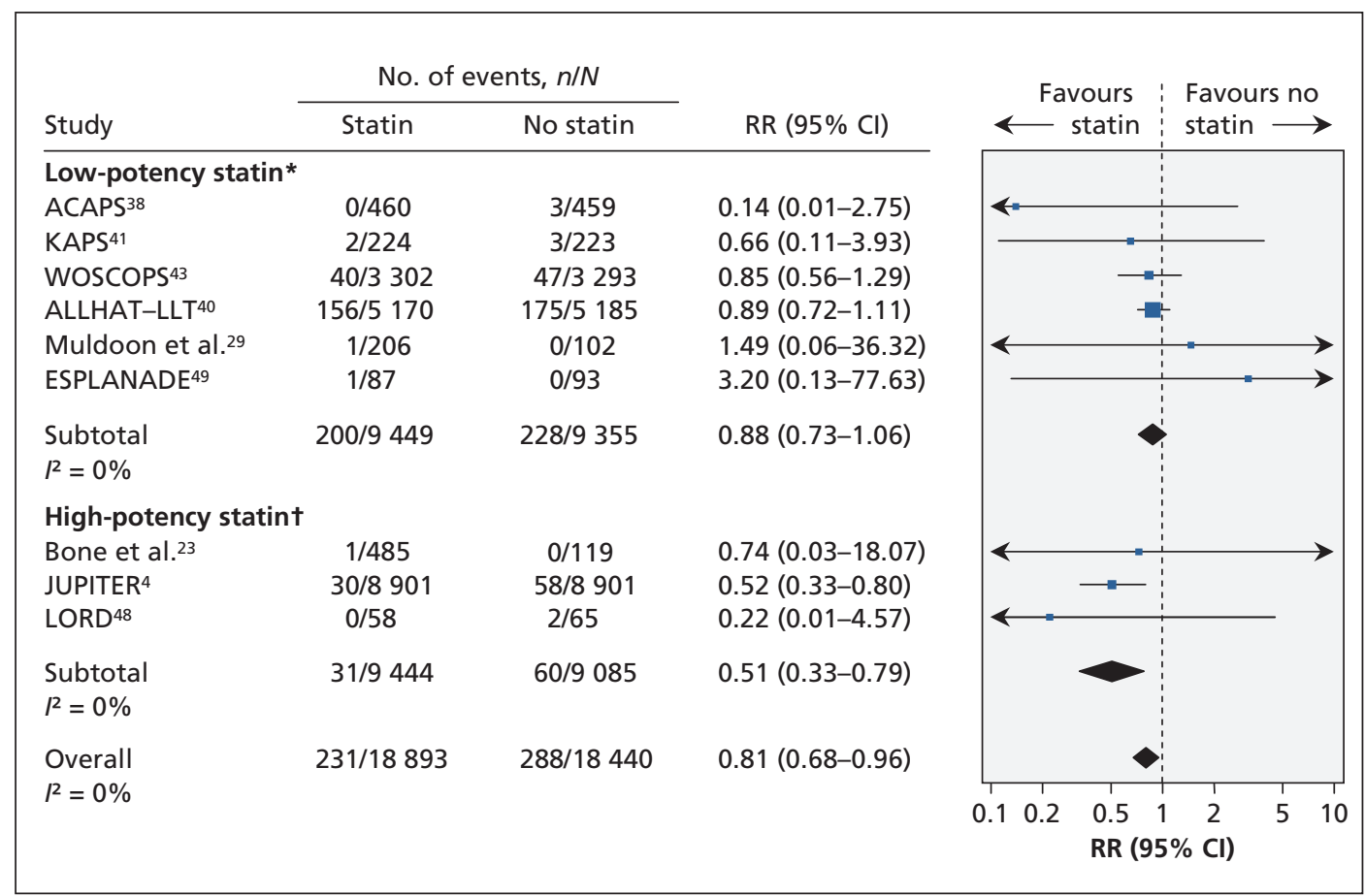

Figure 4: Risk of nonfatal stroke associated with the use of statins (versus no statins) in patients at low cardiovascular risk (observed 10-year risk of cardiovascular-related death or nonfatal myocardial infarction $<20 \%$ ). A relative risk (RR) of less than 1.0 indicates fewer events with the use of statins. $\mathrm{Cl}=$ confidence interval. *Lovastatin, fluvastatin, pravastatin and simvastatin. tRosuvastatin and atorvastatin. For complete study names, see Box 1. 


\section{Adverse events}

Twenty-one trials ( $n=47589$ ) reported the number of participants who had serious adverse events. The trial-level relative risk could not be estimated for four trials that reported no events in either group. From the remaining 17 trials $(n=$ 47021 ), the pooled risk of serious adverse events did not differ significantly between treatment groups (RR 1.01, 95\% CI 0.96-1.07; $I^{2}=8 \%$ ).

Ten trials $(n=45557)$ reported the number of participants who experienced rhabdomyolysis. From the three trials in which this outcome occurred $(n=34712)$, the pooled risk of rhabdomyolysis did not differ significantly between groups (RR 1.29, 95\% CI 0.25-6.68; $F^{2}=0 \%$ ).

Ten trials $(n=62547)$ reported the number of participants in whom cancer was diagnosed, and four trials $(n=31818)$ reported the proportion with new diabetes. The pooled risk of cancer did not differ significantly between groups (RR 1.00, 95\% CI $0.93-1.08 ; I^{2}=0 \%$ ), nor did the pooled risk of diabetes (RR 1.05, 95\% CI 0.84-1.32), although heterogeneity between studies in the latter analysis was large $\left(I^{2}=64 \%\right)$.

\section{Subgroup and sensitivity analyses}

Indirect comparisons between high- and lowpotency statins did not show a significant difference in the risk of all-cause mortality (RR for high- v. low-potency statins: 0.94, 95\% CI 0.791.13), fatal or nonfatal myocardial infarction (RR $0.69,95 \%$ CI $0.43-1.12$ ) or stroke (RR $0.79,95 \%$ CI $0.61-1.02$ ).

The sensitivity analyses, many of which used alternative definitions of low cardiovascular risk, showed findings that were consistent with the results of the primary analysis across a wide variety of assumptions and conditions (Appendices 3 and 4, available at www.cmaj.ca/lookup/suppl/doi: 10.1503/cmaj.101280/-/DC1). In particular, use of estimates rather than observed data to classify trials with respect to 10-year cardiovascular risk led to similar conclusions regarding the efficacy of statins in reducing all-cause mortality. In addition, when low cardiovascular risk was defined as a 10-year risk of cardiovascular-related death or nonfatal myocardial infarction of less than $10 \%$, the pooled relative risk was similar to that of the primary analysis (RR 0.83, 95\% CI 0.73-0.94). The pooled relative risk of all-cause mortality among statin recipients was statistically significant in virtually all of the sensitivity analyses (28 of 33). In addition, the point estimate for the pooled relative risk was relatively stable in these analyses (range 0.78-0.93, as compared with the point estimate of 0.90 in the primary analysis), except for one analysis that included trials with a follow-up period shorter than the median of two years (pooled RR 0.99).

\section{Interpretation}

We found that the use of statins by people at low cardiovascular risk reduced the relative risk of death from any cause by $10 \%$. Treatment with statins also reduced the risk of stroke, myocardial infarction, unstable angina and coronary revascularization to an extent similar to that seen in trials involving patients with coronary artery disease..$^{52}$

In a meta-analysis of the efficacy and safety of statins among patients with coronary artery disease, the number needed to treat was 86 to prevent a single death from any cause and 62 to prevent a single nonfatal myocardial infarction. ${ }^{52}$ The corresponding numbers needed to treat among people at low cardiovascular risk by our primary definition were 239 and 153, which reflect the generally low rates of vascular events in this population. Because statins might be used indefinitely to reduce cardiovascular risk, the absolute benefit may increase (accompanied by corresponding decreases in the number needed to treat) with longer durations of treatment, although this remains speculative.

Although we sought information from all trials on outcomes associated with serious harm from statins, information on serious adverse events was available for only 59\% (47 589/ 80711 ) of the trial participants. This low proportion is consistent with previously documented deficiencies in reporting harm among participants in randomized controlled trials. ${ }^{53,54}$ Our experience with soliciting this information from investigators revealed a lack of clarity among trial authors regarding how serious adverse events were reported in published reports. Because the risk of serious morbidity would be expected to decline among statin users, our finding of a lack of significant difference in the rate of serious adverse events between treatment groups and our nonsignificant estimate of elevated risk among statin users should be interpreted with caution. A complete analysis of published and unpublished data from individual patients on the effect of statins among low-risk patients would be a useful addition to the literature, but it would require cooperation among the various stakeholders.

Our metaregression and indirect comparisons did not show statistically significant differences in the efficacy of high- and low-potency statins. However, metaregression has relatively low statistical power. The as-yet unproven potential for high-potency statins to prevent cardiovascular outcomes more effectively must be balanced against their higher costs compared with lowpotency statins. The recent availability of generic (lower cost) atorvastatin makes this issue of particular importance for decision-makers and thirdparty payers. 
Unlike a recent systematic review that included statin trials involving both low- and highrisk people,${ }^{55}$ we did not find a significantly increased risk of new diabetes among low-risk statin users, perhaps because of differences in study populations or statistical power. If such an effect exists, this would be expected to further reduce the absolute benefit of statin treatment in low-risk populations over the long term.

Our findings also differ from those of another recently published systematic review of 11 trials involving 65229 people without cardiovascular disease that found no evidence of a benefit of statin use on all-cause mortality. ${ }^{56}$ The authors reported a relative risk reduction for all-cause mortality that was similar to ours (9\% v. $10 \%)$, but their estimate was less precise, leading to a 95\% CI that crossed unity (0.83-1.01). Eight trials in that review were included in our study, ${ }^{4,24,28,31,36,39,40,43}$ However, we included an additional 11 trials that reported on all-cause mortality, and we excluded 2 trials $^{57,58}$ that exclusively enrolled participants with a diagnosis of diabetes at baseline. A third study included in the prior reviews was excluded from our study because the 10-year risk for cardiovascular-related death or nonfatal myocardial infarction was greater than $20 \% .^{59}$

\section{Strengths and limitations}

This is an up-to-date, comprehensive systematic review of the clinical implications of statin use among people at low cardiovascular risk. We included studies in which participants were considered to be at low risk according to an accepted definition - a 10-year incidence of less than $20 \%$ for cardiovascular-related death or nonfatal myocardial infarction. ${ }^{10}$ We excluded trials that predominantly enrolled people at higher cardiovascular risk, such as those with diabetes or prior cardiovascular events. Therefore, our relative risk estimates were unlikely to be influenced by higher-risk subgroups within the trial populations.

Our analysis has limitations. First, as with all meta-analyses, our conclusions are limited by the availability of individual trials. We cannot exclude the possibility of publication bias, although it seems unlikely that there are unidentified trials large enough to influence the direction or significance of our findings.

Second, although we used accepted techniques for metaregression in an attempt to identify factors associated with greater or lesser benefit from statin use among low-risk participants, statistical power for these analyses was relatively low given the number of available trials.

Third, the duration of all trials was relatively short given that people at low cardiovascular risk might require treatment with statins for decades.

Fourth, we used the number needed to treat to summarize the benefits of statins across different analyses. Whether the number needed to treat is appropriate for use in meta-analyses is controversial; however, we believe that the simplicity and transparency of this method outweigh its potential disadvantages. ${ }^{21,60}$

Fifth, although we reported a wide range of clinically relevant outcomes as specified in our protocol, the definition for some (e.g., unstable angina) will have varied across trials.

Sixth, in an attempt at unbiased identification of people at low cardiovascular risk, we based our inclusion criterion on the observed incidence of events among placebo recipients, anticipating that clinicians could apply our findings in practice by using their risk prediction instrument of choice to identify patients with an estimated 10-year risk of less than $20 \%$ for cardiovascular-related death or nonfatal myocardial infarction. Because risk prediction tools may overestimate true rates of events in contemporary practice, we repeated analyses after including only trials with an estimated 10year risk of less than $20 \%$ based on mean participant characteristics and two widely used risk equations; ${ }^{11,12}$ we reached similar conclusions.

Finally, given that most of the trials included in our review were at moderate risk of bias, we cannot exclude the possibility that other factors besides statin use may have influenced the observed differences in health outcomes between treatment groups.

\section{Conclusion}

Both low- and high-potency statins were efficacious in preventing death and cardiovascularrelated morbidity in people at low risk of cardiovascular events (whose 10-year risk of cardiovascular-related death or nonfatal myocardial infarction is less than 20\%), most of whom did not have a history of coronary artery disease or diabetes. However, the number needed to treat to prevent one adverse outcome was relatively high for any statin. Whether high-potency statins improve outcomes to a greater extent than lowpotency statins is uncertain based on current data.

\section{References}

1. Cholesterol Treatment Trialists' (CTT) Collaborators, Kearney PM, Blackwell L, et al. Efficacy of cholesterol-lowering therapy in 18,686 people with diabetes in 14 randomised trials of statins: a meta-analysis. Lancet 2008;371:117-25.

2. National Cholesterol Education Program (NCEP) Expert Panel. Detection, evaluation, and treatment of high blood cholesterol in adults (Adult Treatment Panel III). Bethesda (MD): National Institutes of Health; 2002.

3. Genest J, McPherson R, Frohlich J, et al. 2009 Canadian Cardiovascular Society/Canadian guidelines for the diagnosis and treat ment of dyslipidemia and prevention of cardiovascular disease in the adult - 2009 recommendations. Can J Cardiol 2009;25: 567-79. 
4. Ridker PM, Danielson E, Fonseca FA, et al.; JUPITER Study Group. Rosuvastatin to prevent vascular events in men and women with elevated C-reactive protein. N Engl J Med 2008;359:2195-207.

5. Canadian Agency for Drugs and Technologies in Health. Requirements for health technology assessment template for reports. Ottawa (ON): The Agency; 2008.

6. Liberati A, Altman DG, Tetzlaff J, et al. The PRISMA statement for reporting systematic reviews and meta-analyses of studies that evaluate health care interventions: explanation and elaboration. PLoS Med 2009;6:e1000100.

7. Ward S, Lloyd Jones M, Pandor A, et al. A systematic review and economic evaluation of statins for the prevention of coronary events. Health Technol Assess 2007;11:1-160.

8. Pletcher MJ, Lazar L, Bibbins-Domingo K, et al. Comparing impact and cost-effectiveness of primary prevention strategies for lipid-lowering. Ann Intern Med 2009;150:243-54

9. Pearson ES. The application of statistical methods to industrial standardization and quality control. London (UK): British Standards Institution; 1960

10. Grundy SM, Cleeman JI, Merz CN, et al. Implications of recent clinical trials for the National Cholesterol Education Program Adult Treatment Panel III Guidelines. J Am Coll Cardiol 2004; 44:720-32.

11. D'Agostino RB Sr, Vasan RS, Pencina MJ, et al. General cardiovascular risk profile for use in primary care: the Framingham Heart Study. Circulation 2008;117:743-53.

12. Executive Summary of the Third Report of the National Cholesterol Education Program (NCEP) Expert Panel on Detection. Evaluation, and treatment of high blood cholesterol in adults (Adult Treatment Panel III). JAMA 2001;285:2486-97.

13. Juni P, Altman DG, Egger M. Assessing the quality of randomised controlled trials. In: Egger M, Davey Smith G, Altman DG, editors. Systematic reviews in health care. Vol 2. London (UK): BMJ Books; 2001. p. 87-108.

14. Schulz KF, Chalmers I, Hayes RJ, et al. Empirical evidence of bias. JAMA 1995;273:408-12.

15. Jadad AR, Moore RA, Carrol D, et al. Assessing the quality of reports of randomized clinical trials: Is blinding necessary? Control Clin Trials 1996;17:1-12.

16. Cho MK, Bero LA. The quality of drug studies published in symposium proceedings. Ann Intern Med 1996;124:485-9.

17. DerSimonian R, Laird N. Meta-analysis in clinical trials. Contro Clin Trials 1986;7:177-88.

18. Thompson SG, Higgins JP. How should meta-regression analyses be undertaken and interpreted? Stat Med 2002;21:1559-73.

19. Higgins JPT, Thompson SG, Deeks JJ, et al. Measuring inconsistency in meta-analyses. BMJ 2003;327:557-60.

20. Egger M, Davey Smith G, Schneider M, et al. Bias in meta-analysis detected by a simple, graphical test. BMJ 1997;315:629-34

21. Schunemann HJ, Oxman AD, Vist GE, et al. Interpreting result and drawing conclusions. In: Higgins JPT, Green S, editors. Cochrane handbook for systematic reviews of interventions. Oxford (UK): The Cochrane Collaboration; 2011

22. Bucher HC, Guyatt GH, Griffith LE, et al. The results of direct and indirect treatment comparisons in meta-analysis of randomized controlled trials. J Clin Epidemiol 1997;50:683-91.

23. Bone HG, Kiel DP, Lindsay RS, et al. Effects of atorvastatin on bone in postmenopausal women with dyslipidemia: a doubleblind, placebo-controlled, dose-ranging trial. J Clin Endocrinol Metab 2007;92:4671-7.

24. Nakamura H, Arakawa K, Itakura H, et al. Primary prevention of cardiovascular disease with pravastatin in Japan (MEGA Study) a prospective randomised controlled trial. Lancet 2006;368: 1155-63.

25. Di Lullo L, Addesse R, Comegna C, et al. Effects of fluvastatin treatment on lipid profile, $\mathrm{C}$-reactive protein trend, and renal function in dyslipidemic patients with chronic renal failure. $A d v$ Ther 2005;22:601-12

26. Holmberg B, Brannstrom M, Bucht B, et al. Safety and efficacy of atorvastatin in patients with severe renal dysfunction. Scand J Urol Nephrol 2005;39:503-10.

27. Baigent $\mathrm{C}$, Landray M, Leaper C, et al. First United Kingdom Heart and Renal Protection (UK-HARP-I) study: biochemical efficacy and safety of simvastatin and safety of low-dose aspirin in chronic kidney disease. Am J Kidney Dis 2005;45:473-84.

28. Anderssen SA, Hjelstuen AK, Hjermann I, et al. Fluvastatin and lifestyle modification for reduction of carotid intima-media thickness and left ventricular mass progression in drug-treated hypertensives [Hypertension High Risk Management trial (HYRIM)]. Atherosclerosis 2005;178:387-97.

29. Muldoon MF, Ryan CM, Sereika SM, et al. Randomized trial of the effects of simvastatin on cognitive functioning in hypercholesterolemic adults. Am J Med 2004;117:823-9.

30. Zanchetti A, Crepaldi G, Bond MG, et al. Different effects of anti- hypertensive regimens based on fosinopril or hydrochlorothiazide with or without lipid lowering by pravastatin on progression of asymptomatic carotid atherosclerosis: principal results of PHYLLIS — a randomized double-blind trial. Stroke 2004;35:2807-12.

31. Asselbergs FW, Diercks GFH, Hillege HL, et al.; Prevention of Renal and Vascular Endstage Disease Intervention Tria (PREVEND IT) Investigators. Effects of fosinopril and pravastatin on cardiovascular events in subjects with microalbuminuria. Circulation 2004;110:2809-16.

32. Rejnmark L, Buus NH, Vestergaard P, et al. Effects of simvastatin on bone turnover and BMD: a 1-year randomized controlled trial in postmenopausal osteopenic women. J Bone Miner Res 2004;19:737-44

33. Bruckert E, Lievre M, Giral P, et al. Short-term efficacy and safety of extended-release fluvastatin in a large cohort of elderly patients. Am J Geriatr Cardiol 2003;12:225-31.

34. Crouse JR III, Raichlen JS, Riley WA, et al. Effect of rosuvastatin on progression of carotid intima-media thickness in lowrisk individuals with subclinical atherosclerosis: the METEOR trial. JAMA 2007;297:1344-53.

35. Dernellis J, Panaretou M. Effect of C-reactive protein reduction on paroxysmal atrial fibrillation. Am Heart J 2005; 150:1064.

36. Sever PS, Dahlof B, Poulter NR, et al. Prevention of coronary and stroke events with atorvastatin in hypertensive patients who have average or lower-than-average cholesterol concentrations, in the Anglo-Scandinavian Cardiac Outcomes Trial - Lipid Lowering Arm (ASCOT-LLA): a multicentre randomised controlled trial. Lancet. 2003;361:1149-58.

37. Pravastatin use and risk of coronary events and cerebral infarction in japanese men with moderate hypercholesterolemia: the Kyushu Lipid Intervention Study [KLIS]. J Atheroscler Thromb 2000;7:110-21.

38. Furberg CD, Adams HP Jr, Applegate WB, et al. Effect of lovastatin on early carotid atherosclerosis and cardiovascular events. Asymptomatic Carotid Artery Progression Study (ACAPS) Research Group. Circulation 1994;90:1679-87.

39. Downs JR, Clearfield M, Weis S, et al. Primary prevention of acute coronary events with lovastatin in men and women with average cholesterol levels: results of AFCAPS/TexCAPS. Air Force/Texas Coronary Atherosclerosis Prevention Study. JAMA 1998;279:1615-22.

40. ALLHAT Officers and Coordinators for the ALLHAT Collaborative Research Group. Major outcomes in moderately hypercholesterolemic, hypertensive patients randomized to pravastatin vs usual care: The Antihypertensive and Lipid-Lowering Treatment to Prevent Heart Attack Trial (ALLHAT-LLT). JAMA 2002;288:2998-3007.

41. Salonen R, Nyyssonen K, Porkkala E, et al. Kuopio Atherosclerosis Prevention Study (KAPS). A population-based primary preventive trial of the effect of LDL lowering on atherosclerotic progression in carotid and femoral arteries. Circulation 1995;92:1758-64.

42. Mercuri M, Bond MG, Sirtori CR, et al. Pravastatin reduces carotid intima-media thickness progression in an asymptomatic hypercholesterolemic mediterranean population: the Carotid Atherosclerosis Italian Ultrasound Study [CAIUS]. Am J Med 1996;101:627-34.

43. Shepherd J, Cobbe SM, Ford I, et al. Prevention of coronary hear disease with pravastatin in men with hypercholesterolemia. West of Scotland Coronary Prevention Study Group. N Engl J Med 1995; 333:1301-7.

44. Bak AA, Huizer J, Leijten PA, et al. Diet and pravastatin in moderate hypercholesterolaemia: a randomized trial in 215 middleaged men free from cardiovascular disease. J Intern Med 1998; 244:371-8.

45. Bradford RH, Shear CL, Chremos AN, et al. Expanded Clinical Evaluation of Lovastatin (EXCEL) study results. I. Efficacy in modifying plasma lipoproteins and adverse event profile in 8245 patients with moderate hypercholesterolemia. Arch Intern Med 1991;151:43-9.

46. Feldman HH, Doody RS, Kivipelto M, et al. Randomized controlled trial of atorvastatin in mild to moderate Alzheimer disease: LEADe. Neurology 2010;74:956-64

47. Chan KL, Teo K, Dumesnil JG, et al. Effect of lipid lowering with rosuvastatin on progression of aortic stenosis: results of the Aortic Stenosis Progression Observation: Measuring Effects of Rosuvastatin (ASTRONOMER) Trial. Circulation 2010;121:306-14.

48. Fassett RG, Robertson IK, Ball MJ, et al. Effect of atorvastatin on kidney function in chronic kidney disease: a randomised doubleblind placebo-controlled trial [LORD study]. Atherosclerosis 2010;213:218-24

49. Ruggenenti P, Perna A, Tonelli M, et al. Effects of add-on fluvastatin therapy in patients with chronic proteinuric nephropathy on dual renin-angiotensin system blockade: the ESPLANADE trial. Clin J Am Soc Nephrol 2010;5:1928-38. 
50. Yun KH, Shin IS, Park EM, et al. Effect of additional statin therapy on endothelial function and prognosis in patients with vasospastic angina. Korean Circ J 2008;38:638-43.

51. Higgins JPT, Deeks JJ, Altman DG. Special topics in statistics. In: Higgins JPT, Green S, editors. Cochrane handbook for systematic reviews of interventions. 5.1.0 ed. Oxford (UK): The Cochrane Collaboration; 2011.

52. Baigent C, Keech A, Kearney PM, et al. Efficacy and safety of cholesterol-lowering treatment: prospective meta-analysis of data from 90056 participants in 14 randomised trials of statins. Lancet 2005;366:1267-78.

53. Chan AW, Hrobjartsson A, Haahr MT, et al. Empirical evidence for selective reporting of outcomes in randomized trials: comparison of protocols to published articles. JAMA 2004;291:2457-65.

54. Ioannidis JP, Lau J. Completeness of safety reporting in randomized trials: an evaluation of 7 medical areas. JAMA 2001;285:437-43.

55. Sattar N, Preiss D, Murray HM, et al. Statins and risk of incident diabetes: a collaborative meta-analysis of randomised statin trials. Lancet 2010;375:735-42.

56. Ray KK, Seshasai SR, Erqou S, et al. Statins and all-cause mortality in high-risk primary prevention: a meta-analysis of 11 randomized controlled trials involving 65,229 participants. Arch Intern Med 2010;170:1024-31.

57. Colhoun HM, Betteridge DJ, Durrington PN, et al. Primary prevention of cardiovascular disease with atorvastatin in type 2 diabetes in the Collaborative Atorvastatin Diabetes Study (CARDS): multicentre randomised placebo-controlled trial. Lancet 2004; 364:685-96.

58. Knopp RH, d'Emden M, Smilde JG, et al. Efficacy and safety of atorvastatin in the prevention of cardiovascular end points in subjects with type 2 diabetes: the Atorvastatin Study for Prevention of Coronary Heart Disease Endpoints in non-insulin-dependent diabetes mellitus (ASPEN). Diabetes Care 2006;29:1478-85.

59. Shepherd J, Blauw GJ, Murphy MB, et al. Pravastatin in elderly individuals at risk of vascular disease (PROSPER): a randomised controlled trial. Lancet 2002;360:1623-30.

60. McAlister FA. The "number needed to treat" turns 20 - and continues to be used and misused. CMAJ 2008;179:549-53.

Affiliations: From the Department of Medicine (Tonelli, Lloyd, McAlister), University of Alberta, Edmonton, Alta.; the Department of Community Health Sciences (Clement, Hemmelgarn, Manns), University of Calgary, Calgary, Alta.; the Alberta Kidney Disease Network (Tonelli, Lloyd, Conly,
Hemmelgarn, Klarenbach, Wiebe, Manns), Calgary/Edmonton, Alta; the Department of Epidemiology and Community Medicine (Husereau, Klarenbach, Wiebe), University of Ottawa, Ottawa, Ont.; and the Department of Medicine (Hemmelgarn, Manns), University of Calgary, Calgary, Alta. The complete list of members of the Alberta Kidney Disease Network is available at www.akdn.info.

Contributors: All the authors contributed to the conception and design. Marcello Tonelli, Fiona Clement, Braden Manns, Anita Lloyd and Jonathan Conly contributed to the acquisition of data and drafted the report. All of the authors contributed to the analysis and interpretation of data, critically revised the report for important intellectual content and approved the final version submitted for publication.

Funding: This study was jointly funded by the Canadian Agency for Drugs and Technology in Health and the Alberta Heritage Foundation for Medical Research Interdisciplinary Team Grants Program (which supports the Interdisciplinary Chronic Disease Collaboration). The study sponsors had no role in the design of the study, the collection, analysis or interpretation of data, the writing of the report or the decision to submit the article for publication.

Acknowledgements: The authors thank Dr. Steven Grover for his helpful comments on an earlier draft of this manuscript.

Marcello Tonelli, Finlay McAlister and Braden Manns are supported by Alberta Innovates - Health Solutions (formerly the Alberta Heritage Foundation for Medical Research (AHFMR) Health Scholar Awards. Brenda Hemmelgarn and Scott Klarenbach were supported by Population Health Investigator Awards from Alberta Innovates - Health Solutions. Marcello Tonelli was supported by a Government of Canada Research Chair in the optimal care of people with chronic kidney disease. Fiona Clement was supported by a postdoctoral fellowship award from the Canadian Health Services Research Foundation and AHFMR. Marcello Tonelli, Brenda Hemmelgarn, Scott Klarenbach, Finlay McAlister and Braden Manns were supported by an alternative funding plan from the Government of Alberta and the Universities of Alberta and Calgary.

\section{Box 1: Full names of trials included in the meta-analysis}

- ACAPS: Asymptomatic Carotid Artery Progression Study

- AFCAPS/TexCAPS: Air Force/Texas Coronary Atherosclerosis Prevention Study

- ALLHAT-LLT: Antihypertensive and Lipid-Lowering Treatment to Prevent Heart Attack Trial

- ASCOT-LLA: Anglo-Scandinavian Cardiac Outcomes Trial - Lipid Lowering Arm

- ASTRONOMER: Aortic Stenosis Progression Observation: Measuring the Effects of Rosuvastatin

- CAIUS: Carotid Atherosclerosis Italian Ultrasound Study

- ESPLANADE: European Study for Preventing by Lipid-lowering Agents aNd ACE-inhibition Dialysis Endpoints

- EXCEL: Expanded Clinical Evaluation of Lovastatin Study

- HYRIM: Hypertension High-Risk Management Trial

- JUPITER: Justification for the Use of Statins in Prevention: an Intervention Trial Evaluating Rosuvastatin

- KAPS: Kuopio Atherosclerosis Prevention Study

- KLIS: Kyushu Lipid Intervention Study

- LEADe: Lipitor's Effect in Alzheimer's Dementia

- LORD: Lipid Lowering and Onset of Renal Disease

- MEGA: Management of Elevated Cholesterol in the Primary Prevention Group of Adult Japanese

- METEOR: Measuring Effects on Intima-Media Thickness: an Evaluation of Rosuvastatin

- PHYLLIS: Plaque Hypertension Lipid-Lowering Italian Study

- PREVEND-IT: Prevention of Renal and Vascular Endstage Disease Intervention Trial

- UK-HARP-I: First United Kingdom Heart and Renal Protection

- WOSCOPS: West of Scotland Coronary Prevention Study 


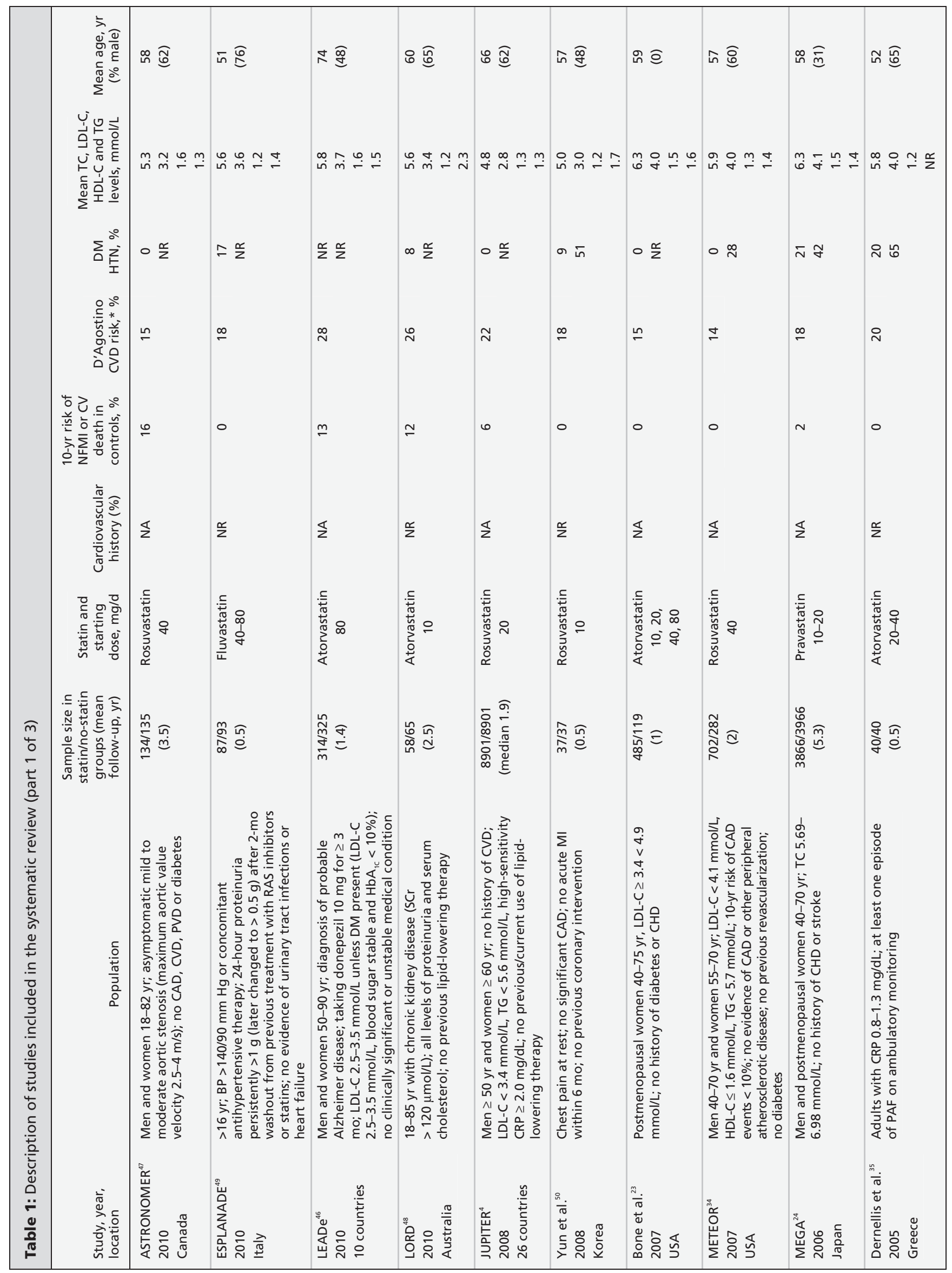




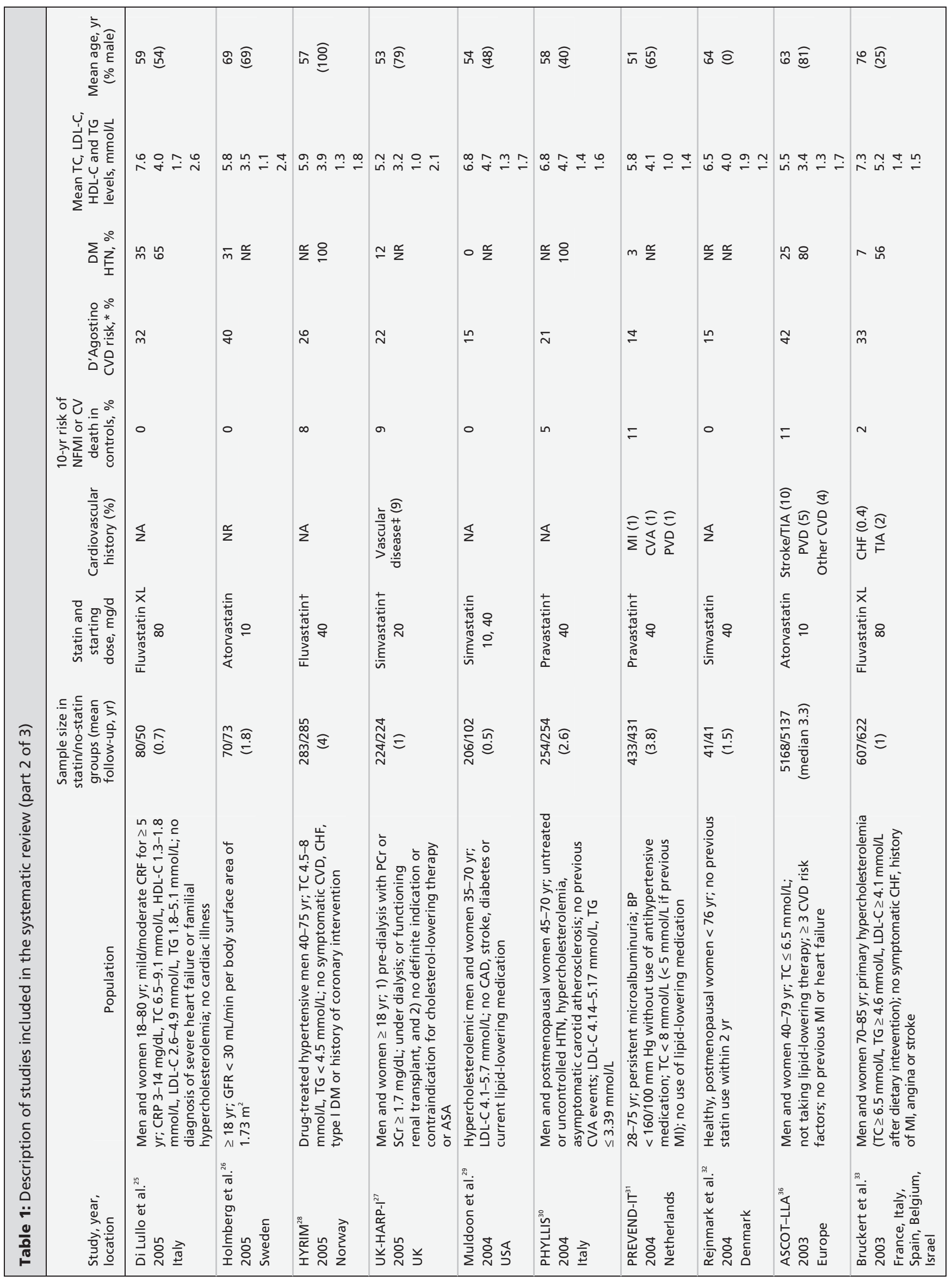




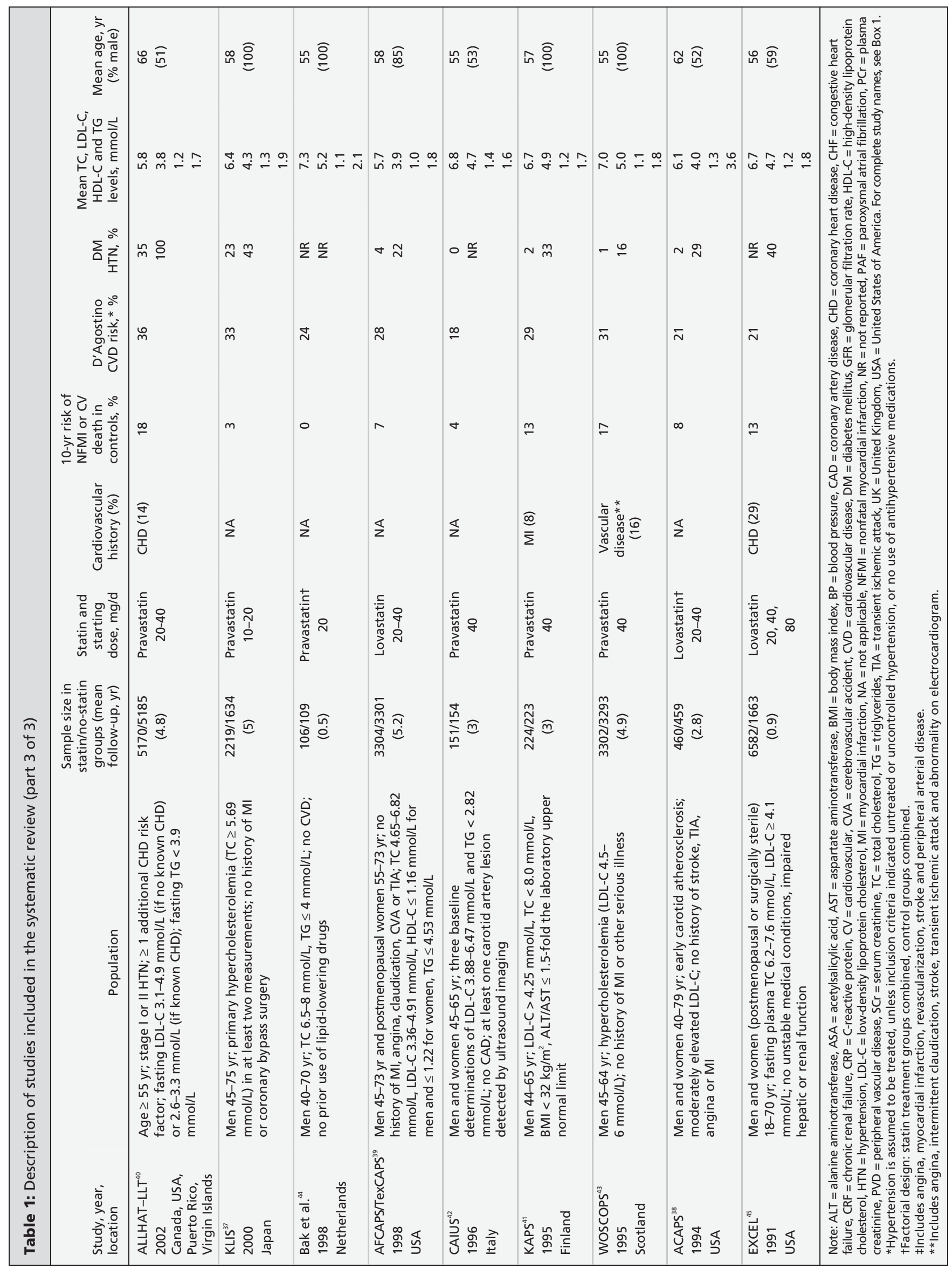




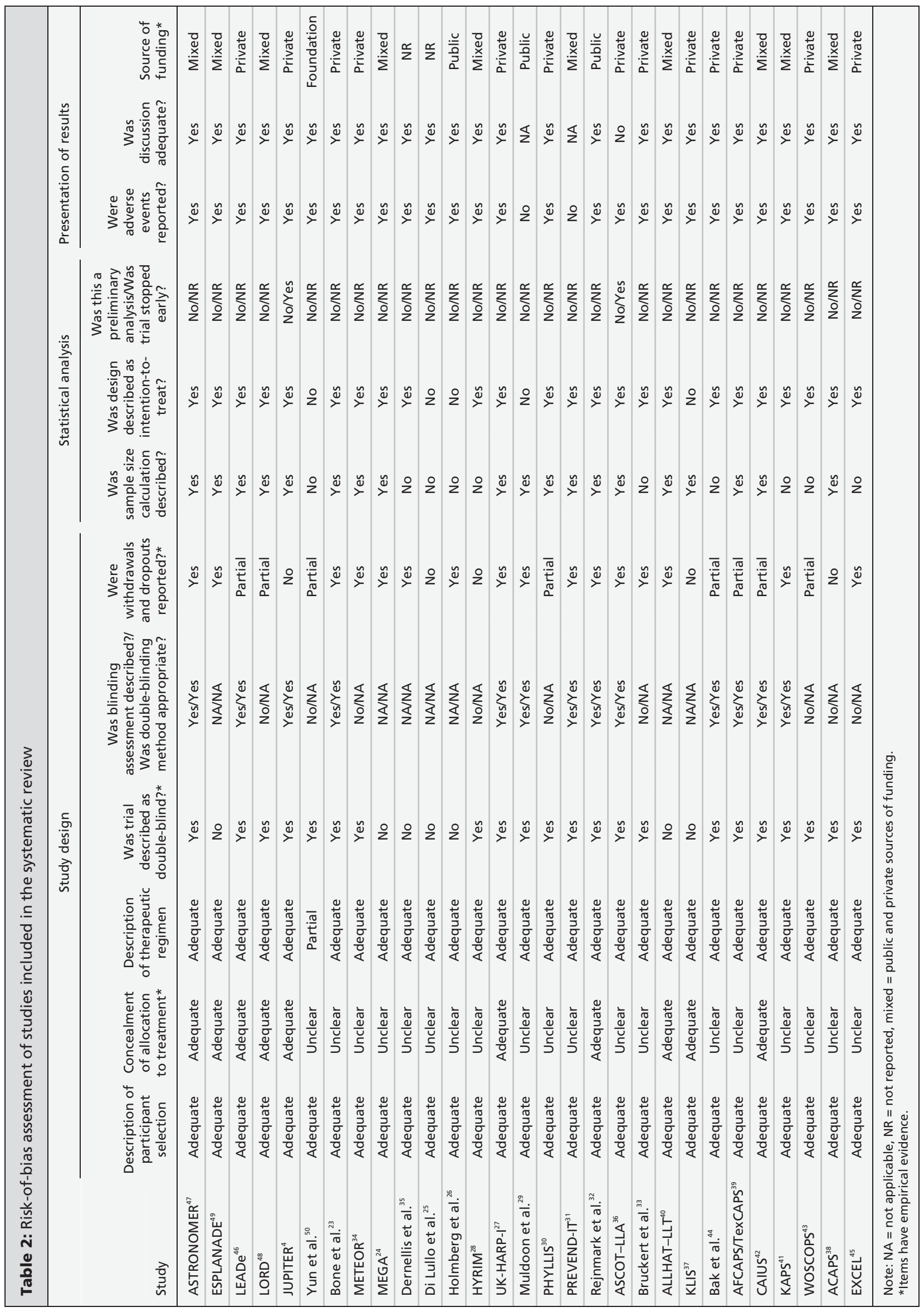

